in the cotton, woollen and worsted industries. This includes a set of diagrams showing graphically to what extent any given illumination is used for each process investigated, and also a number of analytical tables of the results obtained. The third appendix gives a summary of foreign lighting codes, and also a table of the recommendations of the American Illuminating Engineering Society for good lighting practice both general and on the work. These will be found to be considerably higher than the statutory minima for the respective types of work. The fourth appendix gives details of experiments to determine the relative efficiency of artificial light, daylight, and mixed light, carried out in the factory lighting experimental room at the National Physical Laboratory. The fifth and last appendix describes an experimental apparatus for the lighting of glass-bevelling shops, an industry in which complaints have been made as to lighting conditions.

Although much work still remains to be done on this important subject, the present report is a considerable advance on all previous work, and it is to be hoped that legislative measures will pay due attention to the recommendations that accompany it. The report itself should certainly be in the hands of all those who have the management of factories.

\title{
REPORT OF THE DEPARTMENTAL (HOME OFFICE) COMMITTEE ON LIGHTING IN FACTORIES AND WORKSHOPS-THIRD REPORT
}

\section{FORMER RECOMMENDATIONS.}

As our inquiries, owing to the urgent need for economy, are for the present concluded, we think it advisable to repeat here the recommendations we have already made in previous reports.

FIRST REPORT.

In our First Report we recommended that,

1. There should be a statutory provision-

(a) requiring adequate and suitable lighting in general terms in every part of a factory or workshop, and

(b) giving power to the Secretary of State to make Orders defining adequate and suitable illumination for factories and workshops or for any parts thereof or for any processes carried on therein.

We also considered the minimum intensity of illumination desirable for the sake of general convenience and safety in parts of the workshops where work is normally carried on, and in yards, 
passages and open spaces along which people are ordinarily liable to pass, and made the following recommendations :-

2. "Over the ' working areas' of workrooms the illumination measured on a horizontal plane at floor level shall be not less than 0.25 foot-candle, without prejudice to the illumination required for the work itself."

3. "In all parts of iron foundries in which work is carried on, or over which any person is ordinarily liable to pass, the illumination measured on a horizontal plane at floor level shall be not less than 0.4 foot-candle."

4. "In all parts of factories and workshops (not included under recommendation 2 ) over which persons employed are liable to pass, the illumination measured on a horizontal plane at floor level shall be not less than 0.1 foot-candle."

5. "In all open places in which persons are employed during the period between one hour after sunset and one hour before sunrise, and in any dangerous parts of the regular road or way over a yard or other space forming the approach to any place of work, the illumination on a horizontal plane at ground level shall be not less than 0.25 foot-candle."

In exceptional circumstances hardship may be caused by enforcement of the above requirements and, to meet such cases, we recommend that,

6. "There shall be power for the Department to allow exemption in individual cases."

Finally, we recommended that,

7. "All external windows of every workroom shall be kept clean, on both the inner and outer surfaces, but in order to meet exceptional cases as below, there should be power to substitute for the above a definite and binding scheme for cleaning the windows at reasonable fixed intervals, where, for example-

(a) the windows, or some of them (e.g., roof windows), are not readily accessible; or

(b) the total surface of external windows is exceptionally large in relation to the floor space; or .

(c) the conditions of work are such that compliance with the ordinary requirement is, in consequence of the nature of the work, impossible."

Finally, our First Report contained several appendices in which the data obtained by us were summarized.

SECOND REPORT.

In view of part $(b)$ of recommendation 1 , we proceeded, on the resumption of our work in November, 1920, to consider the provisions which should be embodied in any Orders which may 
eventually be made and, in our Second Report, we recommended the following provisions as necessary for ensuring suitability in artificial lighting :-

(A) "Every light source (except one of low brightness") within a distance of 100 feet from any person employed shall be so shaded that no part of the filament, mantle or flame is distinguishable through the shade, unless it be so placed that the angle between the line from the eye to an unshaded part of a source and a horizontal plane is not less than $20^{\circ}$, or in the case of any person employed at a distance of 6 feet or less from the source, not less than $30^{\circ} . "$

(в) "Adequate means shall be taken, either by suitable placing or screening of the light sources, or by some other effective method, to prevent direct deflection of the light from a smooth or polished surface into the eyes of the worker."

(c) "Adequate means shall be taken to prevent the formation of shadows which interfere with the safety or efficiency of any person employed."

(D) "No light sources which flicker or undergo abrupt changes of candle-power in such manner as to interfere with the safety or efficiency of any person employed shall be used for the illumination of a factory or workshop."

We think that all new installations should conform to these requirements, but we recommended-

(E) " That, as regards existing installations, a reasonable time limit should be given before the above requirements become operative."

\section{ADEQUACY OF LIGHTING.}

Our Second Report having dealt with that part of Recommendation $1(b)$ of our First Report which concerns the suitability of lighting, we were left with the important problem of adequacyhow best to secure the " adequate lighting" which we have already recommended should be required by Statute and defined

* By " low brightness" is meant an intrinsic brilliance of not more than five candles per square inch. $t$

+ March, 1922. We now desire to add the following note :-

" Examples of sources of low brightness are a batswing burner, a paraffin flame, etc., and sources of about the same brightness as these are not regarded as coming within the scope of this recommendation.

"It should be remembered that the covering of a brilliant source by a very small shade (such as a silica cup covering a high pressure gas mantle, or a small opal globe surrounding a high-power electric source) may give this shade or globe a brightness three or four times as great as the five candles per square inch, so that it may cause considerable glare and should consequently be treated as a source of light in itself." 
by Order of the Secretary of State for different industrial processes.

It is clearly impossible to specify any one standard of illumination of general application. Lighting requirements vary so much that every process in each industry must be taken into consideration.

Nevertheless we thought it possible that most of the chief processes might be classified in a limited number of groups according to the illumination needed, and thus the whole investigation brought within manageable dimensions.

In dealing with the question of adequacy two alternative courses of procedure present themselves :-

(1) Definite minima may be laid down, below which illumination on any part of the working plane must not fall.

(2) Standards of illumination may be specified as recommended practice, to serve as guides in determining whether lighting is adequate.

Such standards would not be legal minima, but would conform to the best present practice, and would represent figures which may reasonably be expected for the general standard of illumination over the working plane. Till our investigation had made considerable progress, it was impossible to decide which of these alternatives to recommend.

Before deciding on minima such as those referred to in (1), it was necessary to obtain information as to the illumination required for typical processes.

Many data illustrating the existing practice before the war will be found in our First Report, but we felt some doubt as to how far changes had been introduced since that date, especially in textile mills. We therefore arranged for further measurements to be made in such mills. These measurements are tabulated and analysed in Appendix II to this Report.

Besides our own data for factories in the United Kingdom, a certain amount of information is now available about the conditions in other countries. We have examined the Codes of industrial lighting which recently have been given statutory force in many. of the United States of America, and the scales recommended by the German Society of Illuminating Engineers. These are set forth in Appendix III.

With our own measurements and these foreign scales before us, we proceeded, with the assistance of the Factory Department, and in particular of Mr. John Jackson, O.B.E., H.M. Deputy Chief Inspector of Factories, to arrange in two groups the chief processes in the main industries of the country, which require specially good lighting. (See Appendix I.)

In the first group we placed processes involving what we may call "fine work," and in the second group we put processes involving "very fine" work. While we do not claim that the 
schedules we have prepared are complete, they cover a wide range, and we believe them to be substantially correct. We hope that they may be found useful not only by the Home Office, but also by factory occupiers and by those engaged in designing lighting installations.

Our next step was to submit these schedules, with preliminary suggestions for numerical standards of illumination both for them and also for the excluded processes (requiring only moderate illumination), to representatives of the textile, clothing and engineering industries. Our Classification Sub-Committee met representatives of employers and operatives in the cotton and silk industries in Manchester, and of the wool industry in Leeds. Measurements of illumination were made in several mills in the presence of the representatives of the cotton industry, and the representatives of the wool industry undertook to compare our suggestions with measurements made on their own behalf.

The opinions of the representatives of these industries and our own investigations have led us to the conclusion that we cannot at present recommend the enforcement of legal minima of illumination for industrial processes.

Requirements must be kept low if they are to be enforced as legal minima. On a large working plane-such, for instance, as a broad loom-illumination must vary considerably, and points here and there may fall below a.good standard without much harm, if the main area of work is well lit. On the other hand, the general standard of lighting in progressive factories has risen and is rising. It would be unfortunate if a too rigid requirement, which, as we have said, must be put low, tended to stereotype existing conditions, or even to give an excuse for depressing general practice.

The problem is complex. Extensive investigations are necessary before it will be possible to recommend definite minima of illumination to be enforced by legislation. These, owing to the need for economy, we are unable to carry out.

We have accordingly accepted the alternative of specifying standards of illumination as " recommended practice " for " fine" and "very fine" work, rather than definite and legal minima. We now submit the following recommendations :-

(A) In giving effect to the procedure indicated in our First Report for defining adequate illumination for processes carried on in factories and workshops, definite legal minima shall not at present be imposed, but a specification of minimum standards of illumination as " recommended practice" for different groups of processes shall be issued. 
(B) The Schedules A and B given in Appendix I of this Report shall be taken as the basis of this specification; the standard of ill:ımination for processes grouped in Schedule A shall not fall below three foot-candles, and for processes grouped in Schedule B shall not fall below five foot-candles, both schedules and standards being subject to amendment from time to time.

These schedules cover "fine" and "very fine" work.

While with our present information we are unable to frame definite recommendations as regards processes which need only moderate illumination, it must be remembered that, if the recommendations of our First Report are adopted, the illumination at floor level over the working areas of workrooms cannot fall below 0.25 foot-candle. This will give a considerably higher minimum illumination over the working plane, but we are well aware that this will be insufficient for many of the processes excluded from Schedules A and B.

\section{MIXED LIGHTING.}

The subject of mixed lighting (partly artificial light and partly daylight) was brought to our notice by witnesses in giving evidence before the presentation of our First Report, and there appears to be a general impression that it is less satisfactory for certain kinds of work than either daylight or artificial light alone. When working on coloured material, operatives might naturally find difficulties if the two sources were different in quality of light.

We therefore thought it desirable to initiate some experiments in order to obtain definite information on the subject of mixed lighting.

As a first step, the existing conditions in factories and workshops were investigated, measurements of illumination being made in rooms of eight factories, including printing, electric lampmaking, lens-making, dressmaking and millinery workshops.

The artificial light was electric in some cases, and high pressure or low pressure gas in others. The portion of mixed lighting found in actual use-i.e., the ratio of artificial to daylight-varied from $1 / 10$ to $8 / 1$, with an average of $3 / 1$. It appeared that so long as the actual illumination was ample, there was no difficulty in working with a mixed illumination of 100 or one of five foot-. candles, and generally speaking, the operatives interrogated had no definite views on the comfort or otherwise of working with mixed lighting, provided the illumination was not insufficient.

In order to carry out experiments under conditions controlled in a way which would be impossible in a factory, a room was fitted up at the National Physical Laboratory, so that the proportion of daylight and artificial light, as well as the actual amount of each, 
could be carefully regulated. The daylight was variable by alteration of the window screening, while direct, indirect, and semidirect lighting of any desired amount could also be obtained.

Three classes of experiment were carried out in this room. The first series consisted of a test in which the operator marked with a pin a number of small target diagrams printed on white paper, the marks being made regularly to the beat of a metronome. The test depended on a measure of the closeness of the operator's marks to the centres of the targets.

The second series of tests was that of the rate of reading nonpareil type.

The third series consisted of a test of speed and quality in making a certain size of buttonhole in white and black cloth, under artificial light, daylight, and a mixture of 50 per cent. of each kind of lighting. The results of this series of experiments are given in Appendix IV.

No conclusive results indicating any special effects of mixed lighting were obtained however, and, owing to lack of funds, we are unable at present to extend our investigation of this problem. We are, therefore, not prepared to make any definite recommendations on Mixed Lighting at present.

We desire to express our thanks to the firms who co-operated in this inquiry, especially to Messrs. Debenham's, Limited, and to their workers who took part in the last series of experiments.

\section{OTHER QUESTIONS.}

In addition to the main lines of our inquiry, the questions of the best method of lighting glass-bevelling shops, and of the use of translucent instead of transparent glass in factory windows, have been referred to us.

Lighting of Glass-bevelling Shops. This problem was referred to us at the request of a Committee of the Joint Industrial Council for the Furniture Trades.

The bevelling of glass appears to be carried on to a considerable extent by small employers in underground workshops which are, in some cases, very imperfectly lighted. We visited several of these workshops, some of which were illuminated by electric light, whilst others were gas-lighted by means of batswing burners.

The nature of the work necessitates local lighting, which is provided by a lamp placed immediately above and close to the grindstone. Owing to the fact that the workers look directly at the sources of light when examining their work, the source is usually unshaded in the direction of their eyes, and they are, therefore, subjected to unpleasant and often continuous glare. 
Our observations and experiments have satisfied us that a bare light source is unnecessary for examination of the glass during the process of bevelling. We think, therefore, that if recommendation (A) of our Second Report is adopted, compliance with it will necessitate the adoption of a method of lighting (such as that described in Appendix $\mathrm{V}$ to this Report) which will afford adequate protection of the workers from glare.

While we are of opinion that the needs of the case call for the recommendation of no special requirement, other than that referred to, we wish to take this opportunity of emphasising the desirability of carrying on the work of glass-bevelling wherever possible in workshops in which adequate daylight is normally available.

Use of Translucent Glass in Factory Windows. This problem requires investigation of a special character involving psychological considerations. Such an investigation we have not been in a position to carry out.

Contrast. During the course of our experiments on the subject of mixed lighting, the unpleasant effect of undue contrast between the illumination on the work and that on the surroundings was brought again to our notice. The workers complained of a feeling of strain* when there was little general illumination overhead. We wish to take this opportunity of drawing attention to the undesirability of excessive lighting contrast between the surroundings and the point of work.

Effect of Lighting on Accidents. The Chief Inspector of Factories has supplied, for the information of the Committee, particulars of accidents investigated by the Factory Inspectors in the ordinary course of their duty, during two periods of three months, in which defects in lighting appeared to have been a contributory cause. Owing, however, to the depression in industry, the actual number of accidents has been reduced, and very few of them have been attributable to lighting conditions, as very little work has been done in artificial light. The sample, therefore, was not representative of normal times, and to quote the figures would be misleading. It should be stated, however that the Committee were impressed by the large proportion of fatal falls through ships' hatches, due to inadequate lighting of vessels in dock while coaling or under repair, and also by several instances in factories of accidents due to machinery in which a shadow cast upon a danger point was a contributory cause. The Committee are of opinion that further detailed investigation of accidents over a longer period, with special reference to lighting conditions, is desirable. They feel that such an enquiry would be especially valuable as regards accidents due to "persons falling," which

*See Appendix IV, p. 37. 
form a large proportion of the annual total of accidents reported to the Factory Department. The latest published return, that for 1920 , shows that of 138,702 reported accidents $(1,404$ being fatal), 17,393 (372 fatal) were due to " persons falling," including 1,175 (40 fatal) which occurred in docks.

\section{CONCLUSION.}

Finally, whilst we hope that the adoption of the recommendations made in this report will tend to secure more adequate lighting in factories generally, we desire to point out that, in our opinion, much work still remains to be done before the regulation of factory lighting can be established on a basis of definite legal minima for illumination.

We think, indeed, that, if hardship to employers and much administrative difficulty is to be avoided, any such regulation should be preceded by a careful and systematic inquiry conducted on two main lines :-

(i) the collection, for every process concerned, of a sufficient number of observations to give some indication of the best existing practice;

(ii) experimental research with the object of discovering the conditions of illumination desirable on physiological and psychological grounds.

In this respect, we feel that having regard to the wide field to be covered and the complexity of the problems to be considered, little real progress can be expected so long as the whole onus of the work rests upon a single centralized Committee. In particular, the data we have been able to obtain, extensive as they are, are still incomplete in certain industries, even for the specification of advisory standards. We have, for instance, been unable to examine the important subject of the lighting of shipyards, whilst numerous smaller industries and processes remain to be investigated. Ample proof is now forthcoming of the relation between lighting on the one hand and production and safety on the other, and it seems to us not unreasonable to expect active co-operation on the part of all the principal industries in which lighting is specially important. We wish to suggest, therefore, that on the acceptance of this report, the principal industries specified in Appendix I should be invited to assume partial responsibility for the scheme specified above, by arranging for the collection of the actual data, possibly through the Research Associations where they exist. These data, when properly collated by the Committee, in consultation with the industries themselves, could then be used to afford some indication of existing practice, and would form a most valuable 
complement to the more fundamental problem indicated in part (ii) of the scheme, which we suggest should remain under the immediate control of the Committee, namely, experimental research on the conditions of illumination desirable on physiological and psychological grounds.

Owing to existing economic conditions, we are precluded from dealing with these questions at the present time, but we hope that every effort may be made to secure the continuance of our work as soon as circumstances allow.

We wish cordially to thank our two Secretaries, Mr. J. W. T. Walsh and $\mathrm{Mr}$. H. C. Weston, for their services during our inquiry. Our thanks are also due to the Industrial Fatigue Research Board for placing Mr. Weston's services at our disposal.

We are, Sir, Your obedient Servants,

C. Dampier Whetham (Chairman). LEON Gaster.

R. T. Glazebrook.

C. S. Myers.

J. Herbert Parsons.

Rose E. SQuire.

Arthur Whitelegge.

D. R. WILSON.

$\left.\begin{array}{l}\text { H. C. Weston } \\ \text { JohN W. T. WALSh }\end{array}\right\} \begin{gathered}\text { Joint } \\ \text { Secretaries. }\end{gathered}$

\section{ABSTRACTS}

\section{I.-MALPROJECTION OF THE SPATIAL POINT}

Wiseman, E. S.-Cerebral malprojection of the spatial point due to unconscious habit. A mer. Jl. of Physiological Optics, January, 1922.

The author introduces his subject by pointing out that in a small percentage of exophorias a "fusion check" will reveal a homonymous, rather than the customary crossed, diplopia.

He briefly records two cases of his own, which illustrate this fact. 